\title{
Erratum to: Disability, support and long- term social care of an elderly Spanish population, 2008-2009: an epidemiologic analysis
}

\author{
J. Almazán-Isla ${ }^{1,2}$, M. Comín-Comín ${ }^{3}$, E. Alcalde-Cabero ${ }^{1,2}$, C. Ruiz ${ }^{3}$, E. Franco ${ }^{3}$, R. Magallón ${ }^{3}$, J. Damián ${ }^{1,2}$, \\ J. de Pedro-Cuesta ${ }^{1,2^{*}}$, L. A. Larrosa-Montañes ${ }^{4 \wedge}$ and on behalf of the DISCAP-ARAGON Research Group
}

\section{Erratum}

After publication of this article [1], it was noticed that Table 2 contained misalignment of figures. The corrected Table 2, below, contains the same figures as the original, with the numbers shown at bottom right properly aligned. The original article has also been updated to reflect this.

\begin{abstract}
Author details
${ }^{1}$ National Center for Epidemiology, Carlos III Institute of Health, Madrid, Spain. ${ }^{2}$ Consortium for Biomedical Research in Neurodegenerative Diseases (Centro de Investigación Biomédica en Red sobre Enfermedades Neurodegenerativas - CIBERNED), Ministry of Science and Innovation, Madrid, Spain. ${ }^{3}$ School of Health Sciences, University of Zaragoza, Zaragoza, Spain. ${ }^{4}$ Department of Social Services and Family, Aragon Regional Authority, Zaragoza, Spain.
\end{abstract}

Received: 10 April 2017 Accepted: 11 April 2017

Published online: 31 May 2017

\section{Reference}

Almazán-Isla J, Comín-Comín M, Alcalde-Cabero E, Ruiz C, Franco E, Magallón R, Gracia GM. Disability, support and long-term social care of an elderly Spanish population, 2008-2009: an epidemiologic analysis. International Journal for Equity in Health. 2017;16:4. http://doi.org/10.1186/s12939-016-0498-2.

\footnotetext{
* Correspondence: jpedro@isciii.es

Deceased

${ }^{1}$ National Center for Epidemiology, Carlos III Institute of Health, Madrid, Spain

${ }^{2}$ Consortium for Biomedical Research in Neurodegenerative Diseases (Centro de Investigación Biomédica en Red sobre Enfermedades Neurodegenerativas - CIBERNED), Ministry of Science and Innovation, Madrid, Spain
} 


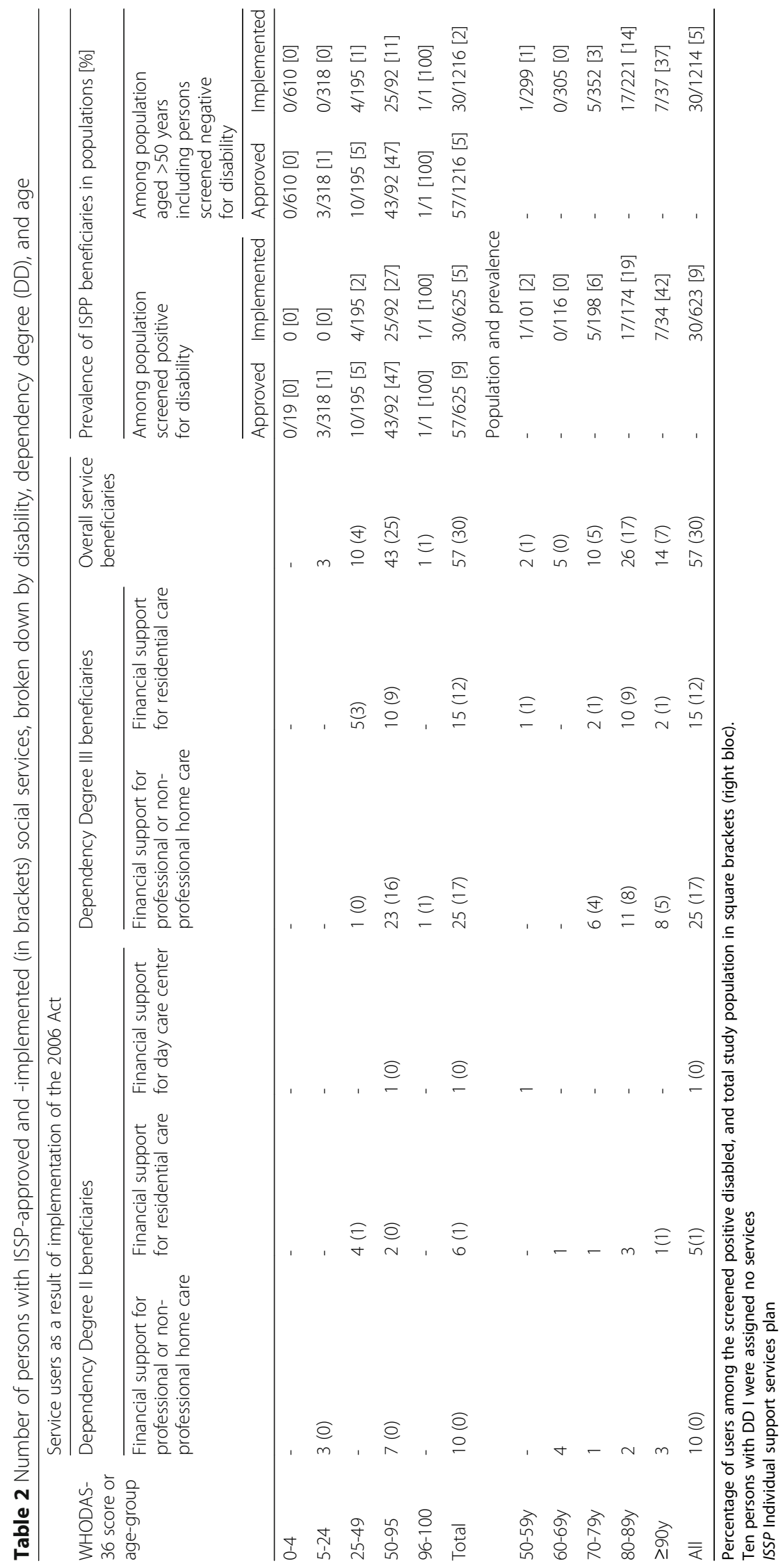

